\title{
Cárie dentária: um novo conceito
}

\author{
José Eduardo de Oliveira Lima*
}

\begin{abstract}
Resumo
Introdução: a maneira como a cárie dentária é conceituada e seus fatores etiológicos considerados têm gerado divergências, na elaboração de estratégias preventivas, entre epidemiologistas e profissionais da saúde. As considerações e o conhecimento sobre a formação, progressão e definição da lesão de cárie devem ser aprofundados, para se estabelecer critérios que favoreçam o diagnóstico, a prevenção e o tratamento, preservando a qualidade de vida do paciente. O conceito de cárie dentária como doença infecciosa, transmissível e dieta dependente deve ser revisto, e os fatores etiológicos melhor interpretados e entendidos, para evitar estratégias de prevenção e tratamento equivocadas. É necessário um posicionamento mais conclusivo de instituições científicas e universidades, objetivando o estabelecimento definitivo desses conceitos, para que possam refletir-se em resultados práticos. Objetivo: o objetivo deste trabalho foi trazer uma contribuição baseada em 35 anos de exercício profissional e da vivência acadêmica no ensino e pesquisa e, também, realizar uma revisão da literatura de Cariologia, com a intenção de levar a uma interpretação dos achados científicos que permita um raciocínio lógico sobre o conceito de cárie dentária e dos fatores envolvidos em sua etiologia, podendo, com isso, chegar o mais próximo possível da verdade. Resultados e Conclusões: os conhecimentos adquiridos até hoje, por meio da pesquisa científica e também a partir das conclusões deste trabalho, permitem elaborar estratégias preventivas mais eficientes em todo o planeta e a cárie dentária passará a ser, dentro de pouco tempo, um problema irrelevante ao ser humano. A partir do raciocínio desenvolvido neste trabalho, pode-se concluir que a cárie dentária não deve ser considerada uma doença, mas simplesmente uma lesão do esmalte de causa local, sem fatores etiológicos determinantes, porém provocada pelo desequilíbrio de fatores considerados fisiológicos, pertencentes à biodiversidade do ser humano e especificamente da cavidade bucal. Uma estratégia objetiva de prevenção deve buscar o equilíbrio biológico, sem perder de vista a qualidade de vida do ser humano.
\end{abstract}

Palavras-chave: Cariologia. Conceito de cárie. Etiologia da cárie.

\section{INTRODUÇÃO}

Será que os conhecimentos adquiridos pela comunidade científica até hoje não são suficientes para resolver o problema da cárie dentária ou, pelo menos, torná-lo irrelevante ao ser humano?

É fundamental conceituar-se a cárie dentária como um processo anormal. É anormal porque um indivíduo que vivia em condições naturais, isto é, o homem primitivo, não desenvolvia uma lesão no esmalte que pudesse ser considerada cárie dentária, por estar inserido em uma biodiversidade comandada pela natureza, em um equi-

* Professor Associado do Departamento de Odontopediatria, Ortodontia e Saúde Coletiva da Faculdade de Odontologia de Bauru - FOB-USP. 
líbrio físico-químico. Apesar de todos os elementos necessários para desenvolver a cárie estarem presentes, havia uma condição de desequilíbrio e reequilíbrio, representados pelo fenômeno da desmineralização e remineralização, mediadas pela saliva, que mantinha a estrutura do esmalte dentário intacta. Essa biodiversidade determinada pela presença de todos os elementos que influenciavam a fisiologia da cavidade bucal em condições naturais, como alimentação, microrganismos e secreção salivar, mantinha o equilíbrio homeostático.

Fica muito difícil entender o equilíbrio proporcionado por essa biodiversidade, com todos os elementos inseridos num processo complexo e, ao mesmo tempo dinâmico, sendo praticamente impossível reproduzir essas condições fora da natureza. Em condições experimentais e artificiais, poderse-ia entender a interferência de um determinado elemento ou substância, numa determinada situação e durante um determinado momento, obtendo conclusões isoladas sem, porém, reproduzir essa biodiversidade, que é tremendamente sensível, se forem consideradas as variações dos hábitos alimentares de um animal para outro, de uma raça para outra ou mesmo de um indivíduo para outro. E é por esse motivo que não se encontram explicações para explanações, algumas vezes, simplistas.

Há milênios, o homem deixou de viver exclusivamente da natureza, quando modificou, de alguma maneira, a forma natural dos alimentos. Gerouse um desequilíbrio da biodiversidade bucal que, a partir desse momento, foi responsável pelo processo de desmineralização e remineralização fora das condições naturais, possibilitando o desenvolvimento de lesões na estrutura dentária chamadas de cárie dentária. É importante considerar que essa biodiversidade produz uma situação de equilíbrio e a cárie dentária nessas condições não existe, devendo, por isso, ser considerada anormal.

Atualmente, não é mais possivel reproduzir a biodiversidade do homem primitivo. No entanto, tem-se a convicção de que quanto mais próximo chegar-se dela, melhor para o ser humano. Todas as estratégias para prevenir a cárie deverão ter, como princípio, produzir o equilíbrio e não gerar qualquer desequilíbrio.

O conceito e o entendimento da etiologia e da patogênese da cárie dentária desenvolveram-se durante o século passado e ainda predominam, sem nenhuma aparente apreciação do crescimento científico exponencial ocorrido durante as últimas décadas, indicando a necessidade de reconsiderações ${ }^{16}$.

Tem-se discutido, na área científica, o envolvimento ultra-estrutural da cárie dentária através de microscopia eletrônica, microrradiografias, microdureza, Imunologia, Biologia Molecular em estudos de Microbiologia, da dinâmica da desmineralização e remineralização, sem que isso represente uma transferência de resultados para a prática clínica com benefícios relevantes ao paciente.

As chamadas "causas indispensáveis" - que têm sido sugeridas como relacionadas à cárie - são, primeiramente, originadas de modelos in vitro, in situ e em animais onde há um rígido controle de fatores complicadores e de condições impostas artificialmente. A cavidade bucal humana não é, entretanto, simulada adequadamente nesses modelos, estando sujeita a diversas e variadas experiências intra e entre indivíduos ${ }^{16}$.

Além disso, observa-se uma aparente controvérsia, tanto em reuniões científicas quanto na literatura, sobre o conceito, fatores etiológicos e diagnóstico da cárie, o que determina diferentes estratégias baseadas em realidades diferentes, com resultados pouco satisfatórios.

Um bom exemplo é a antiga controvérsia relacionada ao conceito de causa e efeito ${ }^{47}$. Está claro que se requer uma definição mais específica sobre a causa determinante da cárie dentária, para que se implementem estratégias de controle mais eficientes, sem que se percam no emaranhado de causas primárias e secundárias, que não podem e, muitas vezes, não precisam de intervenção.

Ainda, no que diz respeito à definição de cárie, há a necessidade de um posicionamento sob o ponto de vista científico, mas principalmente sob 
o ponto de vista do paciente. Um exemplo óbvio é a maneira mais simplificada pela qual a cárie é definida. Há alguns anos, a expressão cárie dentária era utilizada como sinônimo de cavidade cariosa. Atualmente, os profissionais não mais assim a consideram e os pacientes podem, também, através de informações atualizadas, passar a dar importância às lesões incipientes de mancha branca e entender as estratégias preventivas baseadas na característica de reversibilidade da lesão.

O avanço científico, conseguido através de pesquisas que levam em consideração todas as variáveis, que direta e indiretamente podem atuar como fatores que interferem no aparecimento da cárie, provoca confusão, tanto para os profissionais da Odontologia como também para o paciente. Muitas delas foram consideradas tão importantes que, na tentativa de controlar a doença em populações humanas, eram aplicadas em conjunto, sem a devida consideração à racionalidade biológica. Portanto, cabe esclarecer esses temas e tentar explicar como fatores isolados, como microrganismos, dieta e suscetibilidade dentária, podem resultar em conceitos de "causa e efeito" influenciando profundamente a maneira pela qual programas preventivos são projetados ou mantidos, sem efetiva redução da incidência de cárie.

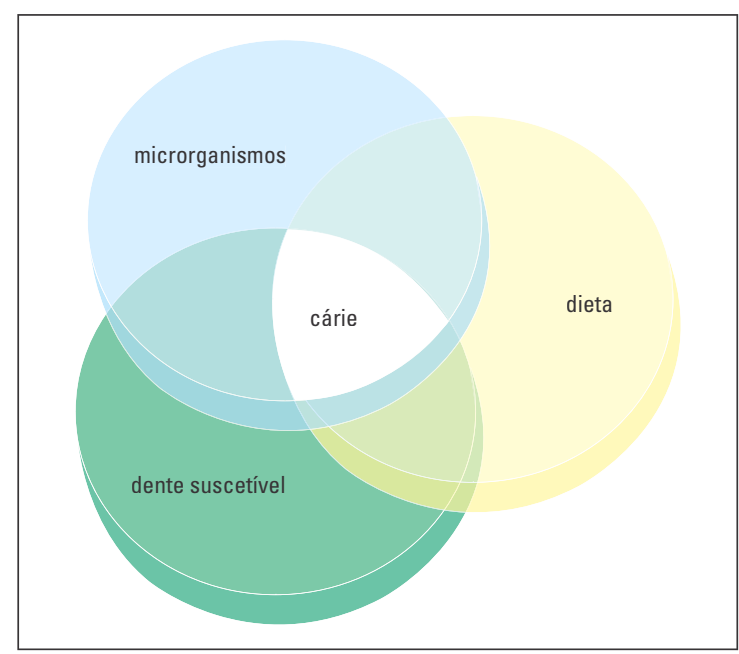

FIGURA 1 - Diagrama de Keyes ${ }^{26}$
É importante, nesse momento, propor-se uma discussão ampla da literatura científica sobre conceitos e fatores etiológicos da cárie dentária com uma interpretação lógica dos achados científicos, e assim contribuir para a solução desse problema que aflige a humanidade, mesmo que isso leve à quebra de paradigmas.

\section{DISCUSSÃO}

\section{Conceito e etiologia da cárie dentária}

A maneira como se conceitua a cárie dentária e seus fatores etiológicos determina a escolha para estabelecer a estratégia preventiva de diagnóstico e tratamento.

É aceito e estabelecido universalmente que a cárie dentária é uma doença multifatorial, infecciosa, transmissivel ${ }^{17,25}$ e dieta dependente, que produz uma desmineralização das estruturas dentárias. Com essa definição, por sua complexidade, torna-se muito difícil compreendê-la completamente.

Esse conceito de cárie é embasado na interação de fatores como dente suscetível, microrganismo e dieta determinando a doença cárie, que foi ilustrada pelo Diagrama de Keyes ${ }^{26}$ (Fig. 1).

Como, para Newbrum ${ }^{39}$, a cárie é resultado de um processo crônico, que aparece após algum tempo da presença e da interação desses três fato-

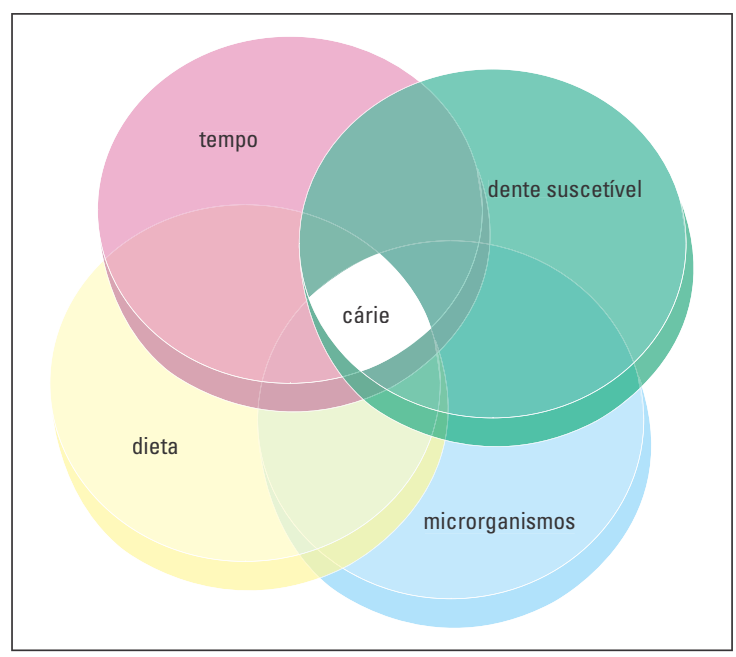

FIGURA 2 - Newbrum ${ }^{39}$ inclui o tempo como outro fator etiológico. 
res, julgou-se conveniente incluir o tempo como outro fator etiológico (Fig. 2).

Porém, todas as estratégias implementadas até agora, baseadas no controle desses fatores, conseguem apenas diminuir a incidência de cárie sem, no entanto, erradicá-la. Isso conduz a um raciocínio controvertido: ou não se consegue interpretar os achados científicos corretamente ou ainda não se estabeleceu um conceito definitivo sobre a "doença". Parece que ambas as hipóteses devem ser consideradas, isto é, o conceito de cárie e o entendimento sobre os seus fatores etiológicos estão incompletos.

Ao aceitar esta afirmativa, deve-se procurar uma conceituação definitiva de cárie dentária e, conseqüentemente, um conhecimento profundo desses fatores etiológicos envolvidos (Fig. 2), que possibilite estabelecer estratégias preventivas mais objetivas, sem que se corra o risco de promover algum desequilíbrio com conseqüências piores do que a própria "doença".

\section{Suscetibilidade}

Quanto ao fator suscetibilidade à cárie, deve-se diferenciar, o que é muito importante, a suscetibilidade do indivíduo como um todo e a do próprio dente. A suscetibilidade do individuo pode ser determinada por fatores extrínsecos e intrínsecos. Os fatores extrínsecos estão relacionados à estrutura sociocultural na qual o indivíduo está inserido como, por exemplo, as diferenças que existem entre as pessoas que vivem em Nova Iorque e aquelas do Tibete. Sabe-se que a suscetibilidade está subjugada a essas diferenças culturais, interferindo no comportamento do indivíduo com influência no controle e na incidência de cárie dentária dessa população. Os fatores intrínsecos (como fluxo, composição e capacidade tampão da saliva, aspectos hereditários e imunológicos), apesar de importantes, são difíceis de serem controlados, não justificando maiores considerações no âmbito das estratégias a serem propostas.

A suscetibilidade do dente à cárie é determinada pelo grau de mineralização do esmalte, propor- cionando maior ou menor resistência à dissolução ácida, cuja mineralização também é regida por fatores intrínsecos que ocorrem durante a formação do dente e os extrínsecos, que são fatores ambientais e locais.

Por muito tempo pensou-se existir dentes resistentes à cárie e muitas tentativas foram feitas para identificar fatores de importância químicoestruturais que explicassem essa suposta resistência ${ }^{12,18,40}$. Também a resistência do esmalte ao ataque ácido não existe, como concluído por Weatherell, Robinson e Hallsworth ${ }^{60}$, em 1983.

A tentativa de aumentar a resistência do esmalte ao ataque ácido ainda faz parte da conduta terapêutica de profissionais, através do uso de substâncias químicas durante a fase pré e póseruptiva do dente, sendo hoje muito contestada a sua eficácia ${ }^{14}$. Pode-se verificar que todos os trabalhos realizados com essa intenção não conseguiram resolver de uma maneira satisfatória o problema da cárie dentária, não sendo capazes de sustentar programas preventivos. Isso não significa que não se deva empregá-los, desde que não ocorra nenhum risco de produzir efeitos colaterais indesejáveis.

Não existe um dente suficientemente resistente à cárie e, por mais que se procure aumentar essa resistência, através de métodos químicos e mecânicos, sempre fica na dependência do desafio cariogênico a que o indivíduo será submetido. Por esse motivo o fator suscetibilidade, no estabelecimento de estratégias preventivas, deve ser considerado como um fator de importância relativa.

\section{Microrganismo}

A importância dada à presença do microrganismo na cavidade bucal, principalmente do es-

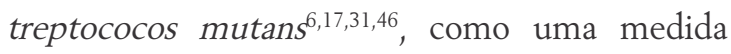
da suscetibilidade do indivíduo à cárie ${ }^{45}$, merece reconsiderações. Sabe-se que esse microrganismo, apesar de ser importante, não é o único que pode participar no desenvolvimento da lesão ${ }^{37,42,52}$ e que somente a sua presença na placa dentária, 
num dado momento, não explica a variação na experiência de cárie ${ }^{54}$, podendo ser facilmente neutralizado com os métodos de controle da placa dentária $^{29,39,51}$. Além disso, um dramático declínio da cárie dentária tem sido documentado, sem uma aparente mudança no nível de estreptococos mutans na saliva ${ }^{4}$.

Muitos trabalhos $5,7,9,13,15,20,27,29,30,39,53,54,55,58$ procuram esclarecer a correlação entre a cárie dentária e a presença de microrganismos, fluxo salivar, capacidade tampão da saliva e sacarose (dieta cariogênica) não chegando a um resultado conclusivo e definitivo em relação à influência desses fatores no controle dessa "doença". A relação, às vezes contraditória, entre esses fatores e a atividade de cárie, já apresentada na literatura, sugere que os métodos de diagnóstico de pacientes de risco sejam revistos ${ }^{52,58}$.

O controle da presença de microrganismos na cavidade bucal influenciando o processo de cárie, ou sendo influenciado por fatores orgânicos salivares, imunológicos e quimioterápicos, não deve ser considerado para o estabelecimento de estratégias preventivas, já que a simples presença de microrganismos na cavidade bucal, seja na saliva ou na placa bacteriana, não é um fator determinante para o aparecimento da "doença" cárie $\mathrm{e}^{55}$. No entanto, a sua participação é inquestionável e indispensável, já que a lesão de cárie passa pelo metabolismo bacteriano, culminando com a formação de ácido e conseqüente desmineralização do esmalte, desencadeando, simplesmente, o processo fisiológico de des-re (desmineralização-remineralização), não determinando, porém, a "doença" cárie.

Sendo assim, deve-se considerar o microrganismo como um fator participativo na etiologia da cárie e não determinante, não se justificando a interpretação da cárie como uma doença infecciosa.

\section{Dieta}

Sabe-se que o homem primitivo, através do consumo de alimentos naturais, desencadeava um processo de des-re em uma situação de equilíbrio que não permitia o aparecimento da "doença" cá- rie. Esses alimentos naturais, apesar de fornecerem uma fonte de carboidratos fermentáveis, também possuem substâncias com ação anti-metabólica, reduzindo esse efeito, além de conterem elementos que potencializam a remineralização, com uma ação anticariogênica ${ }^{10,11,23,38,44}$, proporcionando este equilíbrio. Além desse equilíbrio químico, os alimentos naturais têm uma ação mecânica durante a mastigação, realizando, naturalmente, um controle de placa e, por essas propriedades, eles não são considerados cariogênicos. A manipulação dos alimentos naturais pelo ser humano fez com que muitas dessas propriedades ficassem prejudicadas, produzindo um desequilíbrio da biodiversidade da cavidade bucal, tornando-os cariogênicos.

A cariogenicidade da dieta é determinada pela presença de carboidratos, principalmente a sacarose, que servem de substrato para que os microrganismos da cavidade bucal sintetizem polissacarídeos extracelulares com um importante papel na formação da placa e, também, na produção de ácidos orgânicos, que promovem a desmineralização do esmalte e podem desencadear o processo de cárie $e^{8,36,49}$.

É importante considerar que a desmineralização que ocorre após a ingestão de qualquer dieta cariogênica se dá durante um determinado tempo, até que a capacidade tampão e ação remineralizadora da saliva paralise o processo, não determinando uma lesão de cárie e sim uma simples desmineralização reversivel.

Mas, com a ingestão sistemática e cada vez mais freqüente de alimentos cariogênios pelo ser humano, produzindo um desequilíbrio crescente da des-re, a cárie dentária estabeleceu-se na população mundial de uma forma endêmica, levando-se a concluir que a dieta seria o fator determinante da "doença".

Não se pode negar o importante papel que os alimentos têm na etiologia da cárie dentária, sendo indispensável e inquestionável a necessidade de sua participação, mas também como um fator participativo e não determinante, visto que muitos trabalhos na literatura apresentam resultados inconclusivos quanto a essa relação ${ }^{8,35,36,46,48}$, não 
conseguindo justificar os resultados insatisfatórios de estratégias preventivas baseadas na sua eliminação ou no seu controle.

Assim, pode-se concluir que esses fatores (dente suscetível, microrganismo e dieta), quando presentes na cavidade bucal, não podem ser considerados determinantes da "doença" cárie (Fig. 3).

Sabe-se que a ilustração da figura 3 é hipotética, já que quando presentes na cavidade bucal a interação desses 3 fatores é inevitável. No entanto, essa interação é determinante para a formação da placa bacteriana dentária e não da cárie dentária e que ocorre mesmo em condições naturais, em conseqüência da interatividade desses elementos (Fig. 4).

Sendo assim, a interação desses 3 fatores, considerada determinante para a formação da placa bacteriana dentária, oferece o caráter infeccioso, transmissível e dieta dependente para a placa bacteriana e não à cárie dentária, não podendo esta ser considerada uma "doença" multifatoral, infecciosa, transmissivel e dieta dependente.

O envolvimento desses fatores na formação da placa bacteriana e a sua íntima relação com a etiologia da cárie faz com que autores renomados, como Fejerskov ${ }^{16}$, faça colocações como: "a cárie dentária é uma doença multifatorial, porém de

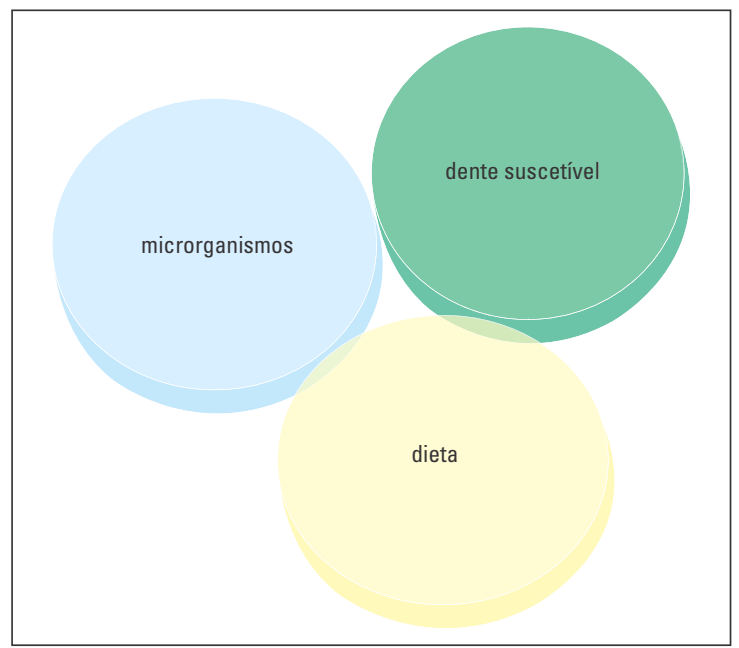

FIGURA 3 - Presença dos 3 fatores sem interação = ausência de lesão. Esses fatores por si só não são determinantes da "doença" cárie, não necessitando de controle, pois fazem parte da biodiversidade da cavidade bucal. uma única causa: a placa bacteriana dentária".

Tendo-se como base a sugestão apresentada por Fejerskov ${ }^{16}$, poder-se-ia acreditar que a placa seria, então, o único fator responsável pela cárie.

Esta hipótese deve-se ao fato de que, sem a presença de placa, não é possível o aparecimento da lesão de cárie, justificando o conceito antigo de que "um dente limpo nunca apresentará cárie".

A presença de placa na superfície do dente também não é um fator determinante para a formação da lesão de cárie, pois, como visto anteriormente, a formação da placa na superfície do dente é um fenômeno fisiológico determinado pela biodiversidade da cavidade bucal e onipresente no ser humano, sendo assim, não se pode exigir que o indivíduo fique isento de placa, sabendo-se que a sua presença na superfície do dente não determina a "doença" cárie (Fig. 5).

Esses depósitos microbianos podem, também, estar presentes na cavidade bucal, na superfície de aparelhos protéticos, exercendo todo o seu potencial cariogênico e culminando com a formação de ácidos sem, porém, provocar a "doença" cárie ${ }^{33}$. Portanto, a definição de placa bacteriana dentária deverá ser aquela formada exclusivamente na superfície do esmalte.

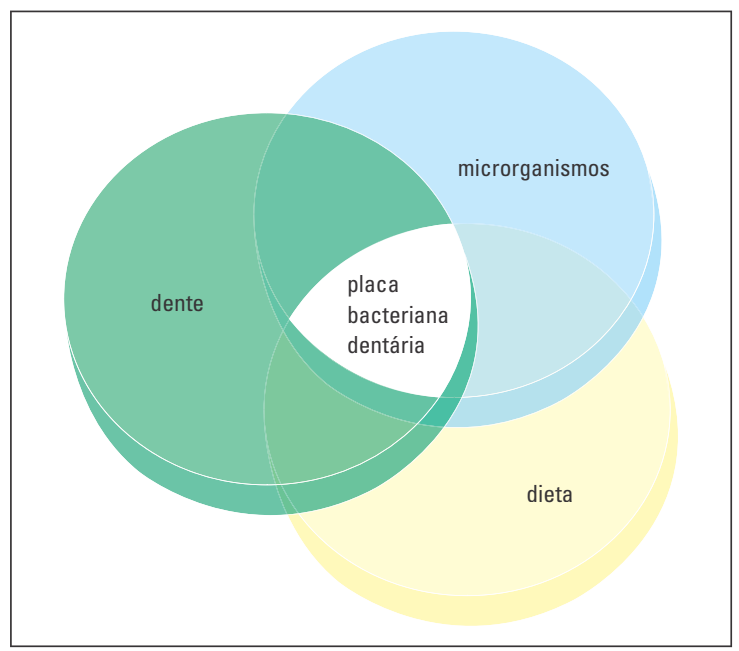

FIGURA 4 - Presença dos 3 fatores de Keyes ${ }^{26}$ com interação, determinando a formação da placa bacteriana dentária, mas não a lesão de cárie. 
Para que a placa bacteriana dentária exerça seu potencial cariogênico, através do metabolismo microbiano, precisará utilizar carboidratos fermentáveis com uma determinada freqüência, produzindo ácido, durante um determinado tempo, capaz de causar uma lesão de cárie. Assim, para que a cárie ocorra, é indispensável a presença de placa, porém, como um fator etiológico específico e não determinante.

Sobre o fator tempo, sugerido por Newbrun ${ }^{39}$, somente será relevante quando houver a presença de placa bacteriana dentária e o indivíduo estiver submetido a uma ingestão freqüente de dieta cariogênica e, assim, o tempo necessário para iniciar a lesão de cárie será inversamente proporcional a essa frequiência. O período de acúmulo de placa bacteriana dentária e a ocorrência de lesões no esmalte já foram estudadas por alguns pesquisadores $^{20,21,43}$, reforçando a idéia dessa relação dependente entre o período de acúmulo de placa e a freqüência de dieta cariogênica.

Cabe salientar, no entanto, dependendo dessa freqüência, ao estabelecer-se um controle mecânico periódico de placa, denominado de "controle períodico" (período de tempo entre um controle de placa e outro), que permita à saliva exercer todo o seu potencial remineralizador, mantendo o equilíbrio da des-re, o tempo para ocorrer uma lesão de cárie pode ser indeterminado. Por esses motivos, o tempo deve ser considerado um fator relativo na etiologia da cárie.

Então que doença é essa que, mesmo na presença desses fatores e de suas interações - considerados até hoje determinantes da "doença" cárie, pois se elaboram estratégias para controlá-los ou eliminá-los - pode não estar presente?

Para elucidar este questionamento, deve-se conceituar a cárie dentária de uma forma objetiva e definitiva e entender a real importância que têm esses fatores na sua etiologia.

Fejerskov $^{16}$ refere-se à cárie não como um evento único, mas como o efeito da acumulação de eventos, um processo que se propaga por um

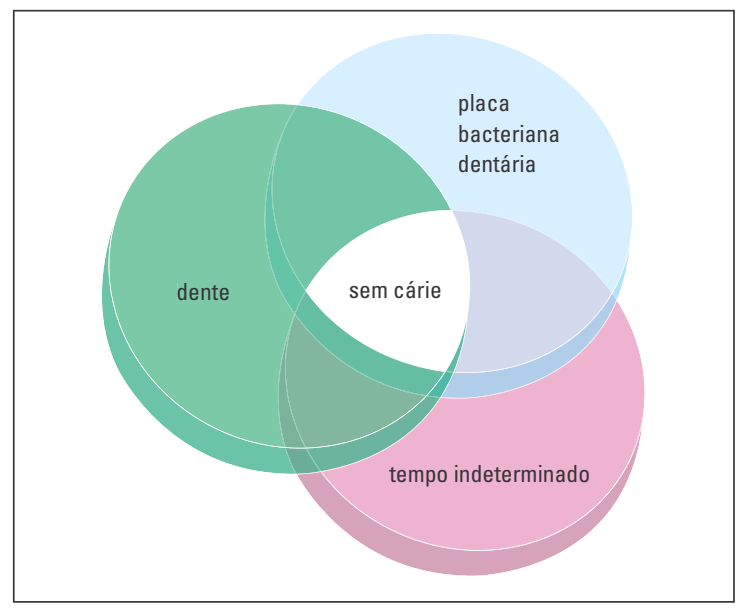

FIGURA 5 - Placa bacteriana dentária ou biofilme bacteriano, presente na superfície do esmalte dentário, não determinando formação de lesão de cárie. Sem a participação de dieta. Tempo indeterminado. Condição hipotética, pois nenhum animal pode ficar sem alimentação por muito tempo.

período de tempo. Para ele, o processo carioso é a dinâmica do fenômeno de des-re resultante do metabolismo microbiano na superfície dentária que, com o passar do tempo, pode resultar em perda de mineral e, possivelmente, mas não invariavelmente, em cavitação.

Deve-se definir cárie dentária como uma desmineralização irreversível do esmalte provocada pelo desequilibrio freqüente do fenômeno de des-re, durante um período de tempo, produzida pela ação de ácidos provenientes do metabolismo de carboidratos na placa bacteriana dentária, e que traz algum prejuízo ao indivíduo, caracterizado por sinais.

É importante considerar que a lesão de esmalte deve ser entendida, não só do ponto de vista científico, que chega a nível ultraestrutural, mas, também, do ponto de vista do paciente, que entende como cárie somente as lesões com sinais.

Portanto, a idéia defendida por este trabalho é a de que uma desmineralização só deverá ser considerada cárie dentária quando se tornar irreversível e com a presença de sinais. Por essas razões, e por se considerar uma simples desmineralização como "doença" cárie, é que existem afirmações equivocadas de que cárie não pode ser prevenida e sim controlada ${ }^{16}$. 


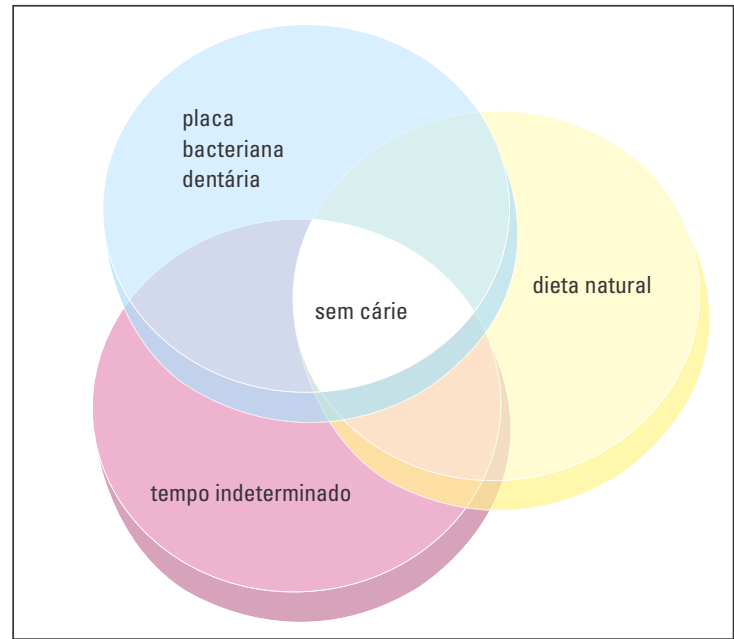

FIGURA 6 - Interação dos três fatores. Processo de des-re em equilíbrio Sem lesão. Tempo indeterminado.

Para se entender o papel destes fatores envolvidos no processo de cárie dentária, isoladamente, e de suas interações, e avaliar a necessidade ou não de eliminá-los ou controlá-los nas estratégias preventivas, deve-se seguir a seguinte lógica.

Sabe-se que, o fenômeno da des-re, produzido pela placa bacteriana dentária e dieta natural, está em equilíbrio, sem causar assim nenhuma lesão relevante no esmalte. Nessas condições, o tempo

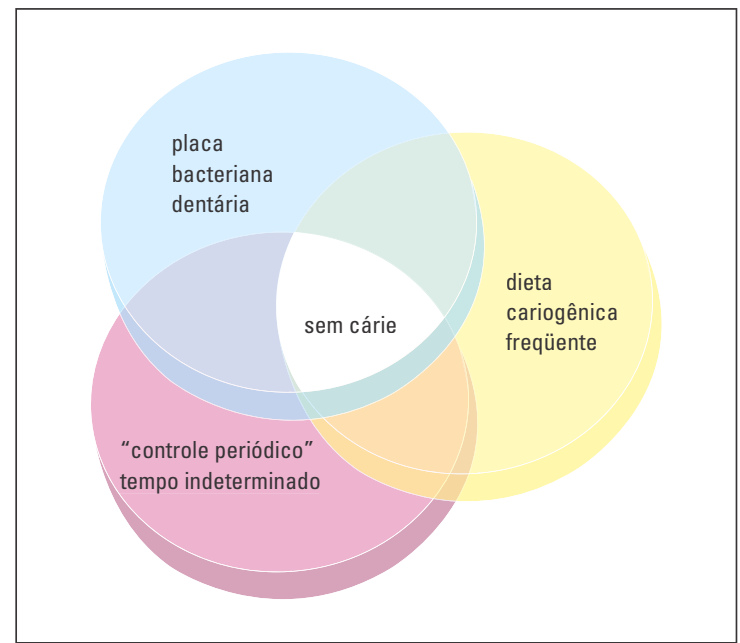

FIGURA 8 - Interação dos três fatores. Ausência de cárie. 0 "controle periódico" é determinado pelo intervalo de controle de placa, que permita a reversibilidade da lesão. Tempo indeterminado.

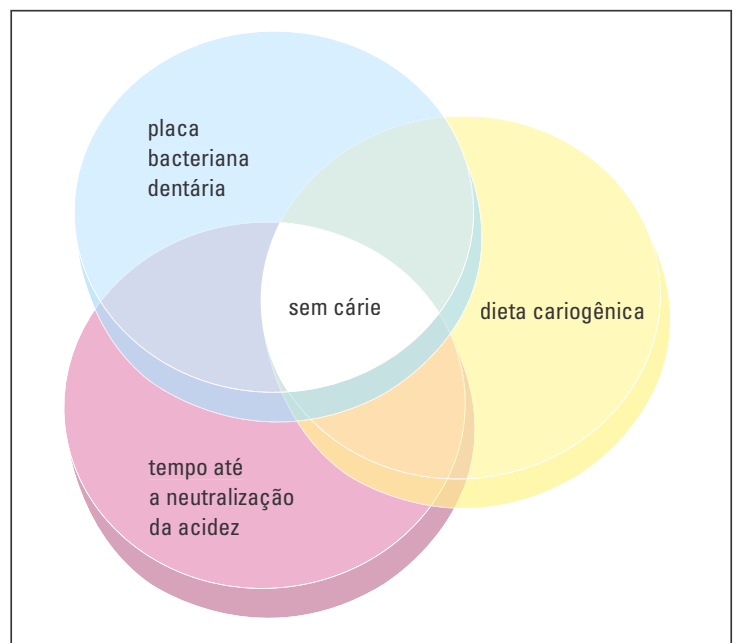

FIGURA 7 - Interação dos três fatores. Fator tempo até a neutralização da acidez pelo sistema tampão salivar. Processo de des-re "em desequilíbrio e reequilíbrio", ausência de lesão.

necessário para a formação de uma lesão de cárie é indeterminado (Fig. 6).

Quando se tem a ingestão de uma dieta cariogênica em presença de placa, em pleno potencial metabólico, ocorre uma desmineralização, porém, o processo de remineralização mediado pela saliva, que funciona como um sistema de defesa do organismo, reverte o processo, voltando às condições iniciais, sem nenhum prejuízo para o esmalte. (Fig. 7).

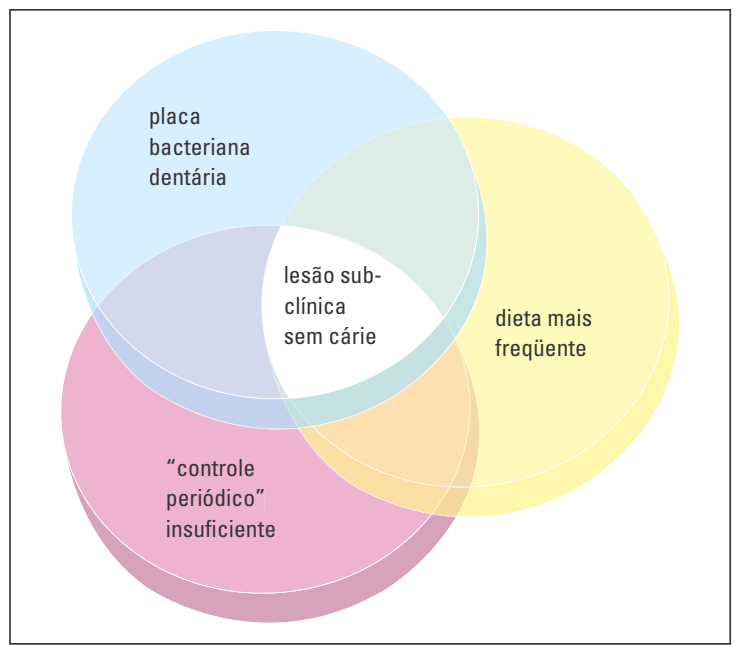

FIGURA 9 - Interação dos três fatores. Formação de lesão irreversível subclínica. Ausência de sinais. Não deve ser considerada cárie. 
Essa desmineralização provocada pelo metabolismo da placa após a ingestão de qualquer dieta cariogênica, não é suficiente para produzir uma lesão de cárie e sim uma simples desmineralização reversível, não necessitando de medidas para evitá-la.

O desequilíbrio da des-re produzido por uma ingestão freqüente de dieta cariogênica, durante um "controle periódico", pode produzir desmineralizações mais severas, porém, ainda reversíveis, sem prejuízo ao esmalte. Nessas condições, o tempo necessário para a formação de uma lesão de cárie pode ser indeterminado (Fig. 8).

O controle mecânico de placa, entendido como a sua total remoção, potencializa a função remineralizadora da saliva, mantendo a lesão do esmalte no estágio reversível por um período indeterminado.

Se o intervalo de tempo de "controle periódico" de placa for insuficiente ou a ingestão de dieta cariogênica for mais freqüente, podem surgir desmineralizações irreversíveis, porém em nível subclínico, não sendo consideradas lesões de cárie, já que se dão com ausência de sinais (Fig. 9).

Se nessas condições de lesão subclínica houver o reequilíbrio da des-re, por meio de um "controle periódico" suficiente ou de uma dieta cariogênica

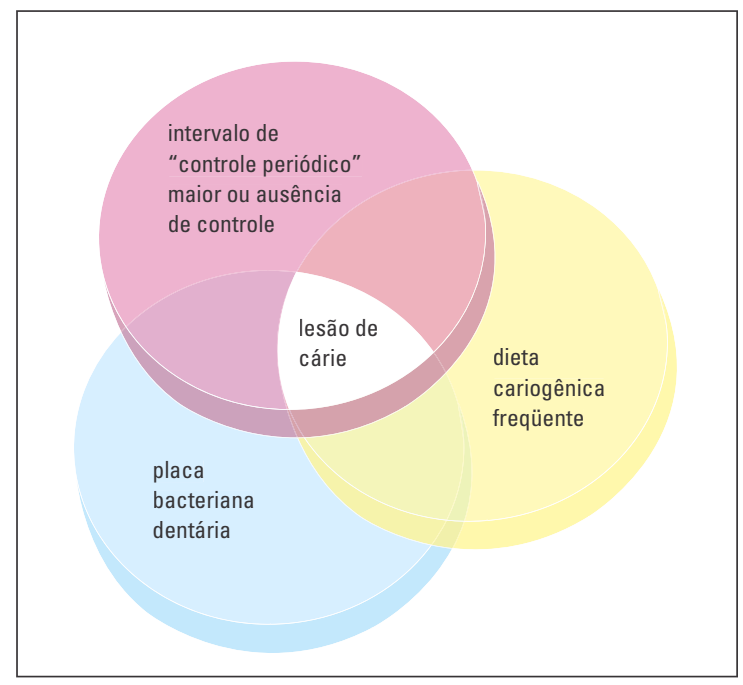

FIGURA 10 - Interação dos três fatores. Formação de lesão irreversível a nível clínico. Presença de sinais. Lesão de cárie. menos freqüente, esta lesão poderá paralisar por um tempo indeterminado, sem chegar a ser diagnosticada como lesão de cárie.

Essa consideração lógica sobre a irreversibilidade da lesão subclínica é devida ao caráter cumulativo das desmineralizações provocadas pelos freqüentes desafios cariogênicos, facilitando o entendimento da progressão da lesão até apresentar sinais.

Assim, se o desequilibrio da des-re continuar por mais tempo, devido a um "controle periódico" com um intervalo de tempo maior ou por ausência de controle e dieta cariogênica freqüente, essa lesão irreversível poderá progredir chegando a nível clínico, com lesões de esmalte, apresentando sinais, determinando uma lesão de cárie. Nesse estágio, deve-se considerar uma lesão de cárie incipiente, mancha branca (Fig. 10).

Quanto maior o desequilíbrio, isto é, quanto maior a freqüência de dieta cariogênica e maior o intervalo de tempo sem controle de placa, mais intensa será a lesão de mancha branca, chegando à cavitação do esmalte, determinando assim, uma lesão de cárie avançada.

Tem sido demonstrado que a efetividade do controle mecânico da placa pode variar, conforme o intervalo de tempo empregado ${ }^{2,3}$.

Assim pode-se concluir que não existe um fator determinante para a instalação de uma lesão de cárie. Dependerá da freqüência de dieta cariogênica e do "controle periódico" de placa, isto é, do desafio cariogênico.

A intensidade do desafio cariogênico só se estabelece pela relação entre freqüência de dieta cariogênica e o "controle periódico" de placa.

Nenhum indivíduo é imune, e sim isento de cárie dentária, enquanto o processo de des-re estiver em equilibrio. Caso contrário, instala-se uma situação de cariogenicidade.

A cárie dentária não deve ser considerada uma doença infecciosa e transmissível, com necessidade de controle químico ou imunológico. Pode, simplesmente, ser chamada de lesão do esmalte dentário provocada por um desequilíbrio químico 
local. Portanto, a lesão de cárie pode ser evitada e controlada mesmo em situações de alta experiência de cárie, a partir da instituição do "controle periódico" de placa, que deverá ser inversamente proporcional à freqüência da dieta cariogênica, permitindo o restabelecimento do equilíbrio da des-re e, desse modo, impedindo que novas lesões atinjam a irreversibilidade.

Deve-se, ainda, levar em consideração a importância de outros fatores que interferem, direta ou indiretamente, no reequilíbrio do fenômeno de des-re, como: fatores salivares, imunológicos, socioeconômicos, culturais, comportamentais, contagem de microrganismo e fluorterapia, porém, considerando-os como fatores de importância relativa no estabelecimento de estratégias preventivas.

Estabelecidos os conceitos de reversibilidade e irreversibilidade da lesão, do diagnóstico a partir de sinais e o entendimento dos fatores etiológicos envolvidos no processo da cárie como sendo fatores de importância relativa, e fatores participativos e específicos e nenhum fator determinante, pode-se estabelecer estratégias preventivas baseadas, simplesmente, no controle mecânico periódico da placa, sem se preocupar com o controle de nenhum outro fator individualmente. $\mathrm{O}$ controle desses fatores, individualmente, deve ser considerado coadjuvante e pode ser implementado desde que não corra nenhum risco de produzir efeitos colaterais que prejudiquem a qualidade de vida do indivíduo, de qualquer outra pessoa envolvida nessa estratégia ou mesmo da própria comunidade.

Baseado no conceito e na etiologia da lesão de cárie aqui estabelecidos, deve-se considerar como cárie dentária somente a lesão de esmalte, desde a sua forma incipiente de mancha branca até a lesão de mancha branca cavitada, quando então pode ser considerada uma lesão de cárie avançada, que poderá progredir e atingir a dentina.

A lesão de dentina, considerada cárie de dentina, é determinada por outros fatores com mecanismo de ação diferente, que leva em conta fatores enzimáticos oriundos de enzimas humanas, da fa- mília das metaloproteinases, as MMPs, que no processo de cárie dentinária compreende as MMP-2, MMP-8, MMP-9 e a MMP-20, responsáveis por degradar várias matrizes de proteínas, incluindo diferentes formas de colágeno. Conclui-se, com isso, que elas participam do processo de cárie na dentina, graças à atividade da telopepitidase, que retira os peptídeos da fibra do colágeno, causando destruição da matriz dentinária, obviamente, após removida a parte mineral pelos ácidos bacterianos $^{1,19,24,34,41,50,56}$. Sabe-se, também, que na lesão de dentina, o fenômeno da desmineralização e degradação da matriz orgânica se dá em momentos diferentes, com ações de estimulação e neutralização entre eles. No entanto, cabe salientar que para a destruição do tecido dentinário há necessidade da atuação dos dois processos. É óbvio que a cárie de dentina é dependente da lesão de esmalte e que o envolvimento dentinário é um ato contínuo, porém determinando um mecanismo de destruição distinto, pois envolve tecidos diferentes. Mesmo a lesão de dentina, também, pode sofrer um processo de paralização e reversibilidade, através da reestruturação deste tecido, no momento em que se consegue um reequilíbrio.

O envolvimento dentinário, pulpar, periodontal e orgânico da lesão dentinária desencadeará um processo inflamatório que poderá ter conseqüências graves, sem nenhuma relação com a lesão de esmalte, a qual participa, apenas, como responsável pelo início do processo.

A partir da proposta desenvolvida neste trabalho e com a certeza de poder estar contribuindo para um melhor entendimento sobre o conceito e os fatores envolvidos no fenômeno da cárie dentária, pode-se estruturar programas preventivos mais eficientes e com uma melhor relação custo-benefício, em qualquer realidade social, proporcionando ao ser humano saúde bucal e melhor qualidade de vida.

\section{CONCLUSÃO}

A partir do raciocínio desenvolvido neste trabalho, pode-se concluir que a cárie dentária não 
deve ser considerada uma doença, mas simplesmente uma lesão do esmalte de causa local, sem fatores etiológicos determinantes, porém provocada pelo desequilibrio de fatores considerados fisiológicos, pertencentes à biodiversidade do ser humano e especificamente da cavidade bucal.

\title{
Dental caries: a new concept
}

\begin{abstract}
Introduction: The concept of dental caries and its etiologic factors have been raising disagreement in the establishment of preventive strategies among epidemiologists and health professionals. Considerations and knowledge on the formation, progression and definition of carious lesions should be enhanced for establishment of criteria to favor the diagnosis, prevention and treatment, maintaining the life quality of patients. The concept of dental caries as an infectious, transmissible and diet-dependent disease should be revised; the etiologic factors should be better interpreted and understood to avoid mistaken approaches for prevention and treatment. A more conclusive positioning of scientific institutions and universities is required for definitive establishment of these concepts and achievement of practical outcomes. Aim: This study aimed to provide a contribution based on 35 years of professional exercise and academic experience in teaching and research, as well as to conduct a literature review on cariology for interpretation of scientific findings to allow logical conclusions on the concept of dental caries and its etiologic factors, to reach the truth as much as possible. Results and Conclusions: The information currently available by means of scientific investigation and also the conclusions of this study allow the formulation of more effective preventive strategies throughout the world allows; in the short term, dental caries will be a minor problem to mankind. Based on the present study, it is concluded that dental caries should not be considered a disease, but rather an enamel lesion due to local causes, without determinant etiologic factors, yet caused by imbalance between physiological factors pertinent to the biodiversity of mankind and specifically to the oral cavity. An objective preventive strategy should aim to achieve biological balance, taking into account the mankind quality of life.
\end{abstract}

Key words: Caries. Caries concept. Caries etiology.

\section{REFERÊNCIAS}

1. ARNOLD, W. H. et al. Morphological analysis and chemical content of natural dentin carious lesion zones. Ann. Anat., New York, v. 185 , no. 5 , p. $419-424$, Oct. 2003

2. AXELSSON, P.: LINDHE, J. The effect of a preventive program on dental plaque, gingivitis and caries in schoolchildren: results after one and two years. J. Clin. Periodontol., Copenhagen, v. 1, p. $126-138,1974$

3. AXELSSON, P.; LINDHE, J. The effect of a plaque control program on gingivitis and dental caries in schoolchildren. J. Dent. Res., Alexandria, v. 56, p. C142-148, 1977. Special issue C.

4. BJARNASON, S. et al. Caries experience in Icelandic 12-year-old urban children 1984 and 1991. Community Dent. Oral Epidemiol., Copenhagen, v. 21, p. 194-197, 1994.

5. BOWDEN, G. H. Does assessment of microbial composition of plaque/saliva allow for diagnosis of disease activity of individuals? Community Dent. Oral Epidemiol., Copenhagen, v. 25, no. 1 , p. 76-81, Feb. 1997

6. BOWDEN, G. H. W. Which bacteria are cariogenic in humans? In: JOHNSON, N. W. (Ed.). Risk markers for oral deseases: dental caries. Cambridge: Cambridge University Press, 1991. p. 266-286.

7. BRETZ,W. A. et al. Relationship of microbial and salivary parameters with dental caries in Brazilian pre-school children. Community Dent. Oral Epidemiol., Copenhagen, v. 20, no. 5 , p. 261-264, Oct. 1992.

8. BURT, B. A. et al. The effects of sugars intake and frequency of ingestion on dental caries increment in a three-year longitudinal study. J. Dent. Res., Alexandria, v. 67, p. 1422-1429, 1988

9. CANTISANO, M. H. et al. Determinação do número de strep- tococcus mutans na saliva de crianças com 6 anos de idade e diferentes experiências de cárie. Estomatol. Cult., Bauru, v. 13, n. 1, p. 44-8, jan./jun. 1983.

10. CARVALHO, D. C. L. Avaliação in vitro do efeito do abacate, Hass, banana prata e maçã Fuji sobre a fermentação e a síntese de polissacarídeos extracelulares da placa dentária humana. 2003. Dissertação (Mestrado)-Faculdade de Odontologia de Bauru, Universidade de São Paulo, Bauru, 2003.

11. CAVAZZOLA, A. S. Avaliação dos efeitos dos chás de camomila, cidreira e erva doce sobre a fermentação e síntese de polissacarídeos na placa dentária humana: estudo in vitro. 2003. Dissertação (Mestrado)-Faculdade de Odontologia de Bauru, Universidade de São Paulo, Bauru, 2003.

12. CEVC, G. et al. The caries resistance of human teeth is determined by the spatial arrangement of hydroxyapatite microcrystals in the enamel. Nature, Basingstoke, v. 286, p. 425-426, 1980.

13. CROSSNER, C. G.; HOLM, A. K. Saliva tests in the prognosis of caries in children. Acta Odontol. Scand., Oslo, v. 37, no. 3, p. $135-138,1977$.

14. CURY, J. A. Uso do flúor e controle da cárie como doença. In: BARATIERI, L. N. et al. Odontologia restauradora. São Paulo: Ed. Santos, 2001. p. 33-68

15. EDGAR, W. M.; HIGHAM, S. M.; MANNING, R. H. Saliva stimulation and caries prevention. Adv. Dent. Res., Washington, D. C. v. 8, no. 2, p. 239-45, July 1994.

16. FEJERSKOV, O. Concepts of dental caries and their consequences for understanding the disease. Community Dent. Oral Epidemiol., Copenhagen, v. 25, no. 1, p. 5-12, Feb. 1997.

17. FITZGERALD, R. J.; KEYES, P. H. Demonstration of the etiologic role of streptococci in experimental caries in the hamster. J. Am. Dent. Assoc., Chicago, v. 61, no. 1, p. 9-19, July 1960.

18. GELLER PALTI, D. Avaliação da desmineralização produzida por desafio cariogênico in situ em esmalte dentário com 
diferentes idades pós-eruptivas. 2007. 103 f. Tese (Doutorado)Faculdade de Odontologia de Bauru, Universidade de São Paulo, Bauru, 2007.

19. HANNAS, A. R. et al. The role of matrix metalloproteinase in the oral environment. 2004.34 f. Trabalho de Conclusão de Curso (Especialização em Odontologia)-Faculdade de Odontologia de Bauru, Universidade de São Paulo, Bauru, 2004

20. HOLMEN, L. et al. A polarized light microscopic study of progressive stages of enamel caries in vivo. Caries Res., Basel, v. 19, no. 4, p. 348-354, 1985

21. HOLMEN, L. et al. A scanning electron microscopic study of progressive stages of enamel caries in vivo. Caries Res., Basel, v. 19 , no. 4, p. 355-367, 1985

22. HONKALA, E. et al. Factors predicting caries risk in children. Scand. J. Dent. Res., Copenhagen, v. 92, no. 2, p. 1334-1340, Apr. 1984.

23. JENSEN, M. E. Diet and dental caries. Dent. Clin. North Am. Philadelphia, v. 43, no. 4, p. 615-633, Oct. 1999

24. KATZ, S.; PARK, K. K.; PALENIK, C. J. In vitro root surface caries studies. J. Oral Med., St. Louis, v. 42, p. 40-48, 1987.

25. KEYES, P. H. The infectious and transmissible nature of experimental dental caries. Arch. Oral Biol., Oxford, v. 1, p. 304-320, 1960

26. KEYES, P. H. Recent advances in dental research: bacteriology. Int. Dent. J., London, v. 12, no. 4, p. 443-464, 1962.

27. KOULOURIDES, T. et al. An intraoral model used for studies of fluoride incorporation in enamel. J. Oral Pathol., Copenhagen, v. 3, p. 185-196, 1974

28. LANZA, C. R. M. et al. Effect of professional dental prophylaxis with sodium bicarbonate jet on the cariogenic microbiota. Pesqui. Odontol. Brás., São Paulo, v. 14, n. 1, p. 87-92, jan./mar. 2000

29. LARMAS, M. Saliva and dental caries: diagnostic tests for normal dental practice. Int. Dent. J., London, v. 42, no. 4, p. 199-208, Aug. 1992

30. LOESCHE, W. J. Clinical and microbiological aspects of chemotherapeutic agents used according to the specific plaque hypothesis. J. Dent. Res., Alexandria, v. 58, no. 12, p. 2404-2412, Dec. 1979.

31. LOESCHE, W. J. Role of streptococcus mutans in human dental decay. Microbiol. Rev., Washington, D. C., v. 50, p. 353-380, 1986.

32. MACPHERSON, L. M. et al. Assessment of the cariogenic potential of streptococcus mutans strains and its relationship to in vivo caries experience. Oral Microbiol. Immunol., Copenhagen v. 7, no. 3, p. 142-147, June 1992

33. MACPHERSON, L. M. et al. Comparison of the plaque microflora from natural and appliance-borne enamel surfaces. Caries Res., Basel, v. 25, no. 1, p. 58-64, 1991

34. MÄKELÄ, M. et al. Matrix metalloproteinases (MMP-2 and MMP-9) of the oral cavity: cellular origin and relationship to periodontal status. J. Dent. Res., Alexandria, v. 73, p. 1397-1406, 1994.

35. MANJI, F. Sugar availability, diet and dental caries. 1988 Thesis. (PhD Thesis)- University of London, London, 1988

36. MANJI, F.; FEJERSKOV, O. Dental caries in developing countries in relation to the appropriate use of fluoride. J. Dent. Res. Alexandria, v. 69, p. 733-741, 1990. Special Issue.

37. MARSH, P. D. Microbial ecology of dental plaque and its significance in health and disease. Adv. Dent. Res., Washington, D. C., v. 8, no. 2, p. 263-271, July 1994.

38. MAZZEO, A. C. et al. Influência do cacau e do leite na incidência de cárie em ratos. Estomatol. Cult., Bauru, v. 15, n. 4, p. 1-4 1985.

39. NEWBRUN, E. Cariology. 2nd ed. Baltimore: Williams \& Wilkins, 1983

40. NIKIFORUK, G. Carbonates and fluorides as chemical determinants of tooth susceptibility to caries. In: SYMPOSIUM, PRESENT STATUS OF CARIES PREVENTION FLUORINE-CONTAINING DENTIFRICES, 1961, Zurich. Abstract... Zurich: [S.I.], 1961. p. 62.

41. NORDBO, $\mathrm{H}$. et al. The influence of a matrix metalloproteinase on the remineralization of artificially demineralized dentin. Oral
Health Prev. Dent., New Malden, v. 1, no. 4, p. 267-72, May/ Oct. 2003

42. NYVAD, B. Microbial colonization of human tooth surfaces. APMIS, Copenhagen, v. 101, no. 32, p.1-45, 1993. Supplement.

43. OGAARD, B.; ROLLA, G.; ARENDS, J. In vivo progress of enamel and root surface lesions under plaque as a function of time. Caries Res., Basel, v. 22, p. 302-305, 1988.

44. PRESTES, M. P. Avaliação do efeito dos leites materno, de vaca e de cabra sobre a fermentação e síntese de polissacarídeos na placa dentária humana. Estudo in vitro. 2003. Dissertação (Mestrado)-Faculdade de Odontologia de Bauru, Universidade de São Paulo, Bauru, 2003.

45. RODRIGUEZ, F. E. Quantitative incidence of lactobacillus acidophilus in the oral cavity as a presumptive index of susceptibility to dental caries. J. Am. Dent. Assoc., Chicago, v. 18, p. 2118-35, 1931.

46. ROSE, G. Sick individuals and sick populations. Int. J. Epidemiol., London, v. 14, p. 32-38, 1985.

47. ROTHMAN, K. J. Causes. Am. J. Epidemiol., Baltimore, v. 104, p. 587-592, 1976.

48. RUGG-GUNN, A. J. et al. Relationship between dietary habits and caries increment assessed over two years in 405 English adolescent school children. Arch. Oral Biol., Oxford, v. 29, p. 983-992, 1984.

49. SREEBNY, L. M. Sugar and human dental caries. World Rev. Nutr. Diet., Basel, v. 40, p. 19-65, 1982.

50. SULKALA, M. et al. The localization of matrix metalloproteinase-20 (MMP-20, Enamelysin) in mature human teeth. J. Dent. Res., Alexandria, v. 81, no. 9, p. 603-607, Jan./July 2002

51. SULLIVAN, A. On the applicability of the number of mutans streptococci and lactobacilli in saliva and plaque for the prediction and explanation of dental caries. 1995. Thesis. (PhD Thesis)-School of Dentistry, Malmö, 1995.

52. SULLIVAN, A. et al. Number of mutans streptococci or lactobacilli in a total dental plaque sample does not explain the variation in caries better than the numbers in stimulated whole saliva. Community Dent. Oral Epidemiol., Copenhagen, v. 24, no. 3, p. 159-163, 1996.

53. TENOVUO, J. Salivary parameters of relevance for assessing caries activity in individuals and populations. Community Dent. Oral Epidemiol., Copenhagen, v. 25, no. 1, p. 82-86, 1997

54. TENUTA, L. M. A. LIMA J. E. O. CARDOSO C. L. TAB CHOURY, C. P. M.; CURY, J. A. Effect of period of plaque accumulation and salivary factors on enamel demineralization and plaque composition in situ. Pesqui. Odontol. Brás., São Paulo, v. 17 , no. 4 , p. $326-331,2003$

55. THYLSTRUP, A.; FEJERSKOV, O. Cariologia clínica. 2. ed. São Paulo: Ed. Santos, 1995

56. TJÄDERHANE, L. et al. The activation and function of host matrix metalloproteinases in dentin matrix breakdown in caries lesions. J. Dent. Res., Alexandria, v. 77, no. 8, p. 1622-1629, Aug. 1998

57. TUKIA-KULMALA, H.; TENOVUO, J. Intra and inter-individual variation in salivary flow rate, buffer effect, lactobacilli and mutans streptococci among 11- and 12-year-old schoolchildren. Acta Odontol. Scand., Oslo, v. 51, no. 1, p. 31-7, Feb. 1993

58. VAN HOUTE, J. Microbiological predictors of caries risk. Adv. Dent. Res., Washington, D.C., v. 7, no. 2, p. 87-96, Aug. 1993.

59. VAN STRIJP, A. J. P.; VAN STEENBERGEN, T. J. M.; TEN CATE, J. $M$. Bacterial colonization of mineralized and completely demineralized dentine in situ. Caries Res., Basel, v. 31, p. 349-355, 1997.

60. WEATHERELL, J. A.; ROBINSON, C.; HALLSWORTH, A. S. Formation of lesions in enamel using moist acid vapour. In: LEACH, S. A.; EDGAR, W. M. Demineralization and remineralization of the teeth. Oxford: IRL Press, 1983. p. 225-241.

\section{Endereço para correspondência}

José Eduardo de Oliveira Lima

Al. Octávio Pinheiro Brisola, 9-75

CEP: 17.012-901 - Bauru / SP

E-mail: jeduardo895@terra.com.br 